violence in dating relationships perpetrated by secondary-school adolescents in 10 Brazilian cities. The hypothesis is that reciprocity pattern prevails and that female adolescents show the highest rates of perpetration. A sample of 3205 adolescents, aged 15-19, from state to private schools, was investigated, using the Conflict in Adolescent Dating Relationships Inventory. The majority of participants were female adolescents (59\%). The prevalence of violence perpetrated by male adolescents stood at $22.4 \%$, whereas for the female participants it was $39.4 \%$. The analysis of the directionality pattern shows that in most relationships both partners practiced aggression, corroborating the evidence for violence reciprocity. This pattern was found in four out of the ten cities, while in the other six, violence perpetrated by female adolescents reached the highest prevalence rates (average of $43.1 \%$ ). However, in all ten cities, violence perpetrated only by male adolescents shows lower prevalence levels, reaching an average of $9.7 \%$. In line with other studies in Brazil and the USA, female adolescents seem to be more violent than male teenagers, contradicting common sense and the findings from studies on violence among adult couples, in which case women are the main victims. Further investigation is needed into the following aspects: severity and frequency of violent acts; evolution of violence dynamics from dating to adult relationships; and the underlying reasons and context in which violence occurs.

\section{P1-400 INFANT MORTALITY FROM PREVENTABLE CAUSES IN BRAZIL: AN ECOLOGICAL STUDY}

doi:10.1136/jech.2011.142976f.91

A Boing, , A Boing. Federal University of Santa Catarina, Florianópolis, Santa Catarina, Brazil

Infant mortality is a major public health issue in developing countries. This study aims to test the associations between infant mortality from preventable causes in Brazil and socioeconomic factors, including those pertaining to health services and investments. This was an ecological study using data from 2000 to 2002. 296 Brazilian counties (municipalities) with more than 80000 inhabitants each were the analytical units. Kruskall-Wallis and ANOVA tests were performed to compare independent variables according to infant mortality quartile, and Pearson and Spearman's correlation coefficients were computed to test the associations. As the infant mortality quartile from preventable causes increases, there is a gradual decrease in the municipal human development index, per capita gross domestic product, households with bathrooms and indoor plumbing, total health expenditures per inhabitant, and physicians per 1000 inhabitants, and an increase in the Gini coefficient. Improved socioeconomic conditions and public health investments are strongly associated with reduction of infant mortality from preventable causes. This knowledge should permeate actions aimed at minimising the number and unequal distribution of such deaths.

\section{P1-401 TEMPORAL TREND IN AND SPATIAL DISTRIBUTION OF LUNG CANCER MORTALITY IN BRAZIL BETWEEN 1979 AND 2004: MAGNITUDE, REGIONAL PATTERNS, AND GENDER- RELATED DIFFERENCES}

doi:10.1136/jech.2011.142976f.92

A F Boing, ${ }^{*}$ T F Rossi. Federal University of Santa Catarina, Florianópolis, Santa Catarina, Brazil

Introduction Lung cancer is a major public health problem in Brazil. The aim of this study was to describe the temporal trend and the spatial distribution of mortality from tracheal, bronchial, and lung cancer in Brazil from 1979 to 2004.

Methods Mortality data by gender and geographic region were obtained from the Mortality Database created by the Ministry of Health in 1975. Demographic data were collected from the national censuses, from population counts, and from population estimates made in non-census years. Mortality rates were standardised according to the direct method, and the trends were analysed by gender and geographic region using the Prais-Winsten method for generalised linear regression.

Results Lung cancer mortality accounted for approximately $12 \%$ of the overall neoplasia-related mortality during the period. There was a trend towards an increase for both genders and in all regions, except for the male population in the southeast region, whose rates remained steady between 1979 and 2004 . The highest rates were observed in the south and southeast regions. However, the northeast region was the one that presented the greatest increase, followed by the central-west and north regions. In all regions, the increase in mortality rates was higher in women.

Conclusion The increase in lung cancer mortality in Brazil between 1979 and 2004 requires public measures that can minimise exposition to risk factors, mainly tobacco, and allow greater access to healthcare facilities for diagnosis and treatment.

\section{P1-402 PSYCHOSOCIAL PATHWAYS TO MENTAL WELL-BEING IN DEPRIVED AREAS}

doi:10.1136/jech.2011.142976f.93

${ }^{1} \mathrm{~L}$ Bond, ${ }^{* 1,2} \mathrm{~A}$ Kearns, ${ }^{1,2} \mathrm{P}$ Mason, ${ }^{1,3} \mathrm{C}$ Tannahill, ${ }^{1} \mathrm{M}$ Egan, ${ }^{1,2} \mathrm{E}$ Whitley. ${ }^{1} \mathrm{MRC} / \mathrm{CSO}$ Social \& Public Health Sciences Unit, Glasgow, UK; ${ }^{2}$ University of Glasgow, Glasgow, UK; ${ }^{3}$ Glasgow Centre for Population Health, Glasgow, UK

Introduction Housing-led regeneration has been shown to have limited effects on mental health. Considering neighbourhoods as a psychosocial environment, regeneration may have greater impact on mental well-being than mental ill-health. This study examined the relationship between the well-being of residents living in deprived areas and aspects of housing, neighbourhoods and communities.

Methods A cross-sectional study of 3911 residents in 15 deprived areas in Glasgow, Scotland. Mental well-being was measured using the Warwick Edinburgh Mental Well-being Scale.

Results Using multivariate analysis and controlling for sociodemographic characteristics and physical health status, we found that residential and environmental aspects of people's houses and neighbourhoods were strongly associated with wellbeing: when respondents considered that their neighbourhood had very good aesthetic qualities (RR 3.3, 95\% CI 1.9 to 5.8), their home and neighbourhood represented personal progress (RR 3.2 $95 \%$ CI 2.2 to 4.8 ; RR 2.6, 95\% CI 1.8 to 3.7 , respectively), they perceived their residence to have a very good external appearance (RR 2.6, 95\% CI 1.3 to 5.1); a very good front door (both an aesthetic and a security/control item) (RR 2.1, 95\% CI 1.2 to 3.8$)$, and satisfaction with their landlord was very high (RR 2.3, 95\% CI 2.2 to 4.8). Perception of poor neighbourhood aesthetic quality was associated with lower well-being (RR 0.4, 95\% CI 0.3 to 0.5 )

Discussion This study has found that where we live matters for mental well-being. In particular, it appears that positive residential circumstances may influence how we feel about ourselves and our view of our position in society, with beneficial consequences for well-being.

\section{P1-403 WITHDRAWN}

